model has limitations. At present there are inadequate good-quality data to provide reliable information about the behaviour of clay under general three-dimensional conditions of stress with rotation of the principal axes. Even if this information were forthcoming, any mathematical model that incorporated such behaviour would be unusually complex. The virtue of the Cam-clay model is that it is a complete, self-consistent model which represents the salient features of the behaviour of clay and, in particular, up-dates the current undrained strength as consolidation occurs. It is believed that the work discussed in the Paper is the first in which pile capacity can be estimated both in terms of effective stresses by taking account of the effects of driving and subsequent consolidation, and as to how it changes with time after installation. This has been achieved with the use of one consistent model for all the stages of installation. It is not claimed that the results are other than qualitatively relevant to the problems of the design of piles, much further research is needed before accurate quantitative predictions can be made.

\section{REFERENCES}

Carter, J. P., Randolph, M. F. \& Wroth, C. P. (1979) Stress and pore pressure changes in clay during and after expansion of a cylindrical cavity. Int. $J / \mathrm{Num}$. Anal. Meth. Geomech. 3, 305-322.

Eide, O., Hutchinson, J. N. \& Landva, A. (1961). Short and long term test loading of a friction pile in clay. Proc. 5th Int. Conf. Soil Mech., Paris, 45-54.

Koizumi, Y.\& Ito, K. (1967). Field tests with regard to pile driving and bearing capacity of piled foundations. Soil Fdn 7, No. 3.

Randolph, M. F. \& Wroth, C. P. (1979). An analytical solution for the consolidation around a driven pile. Int. Il Num. Anal. Meth. Geomech. 3, 217-229.

Randolph, M. F.\& Wroth, C. P.(1981). Application of the failure state in undrained simple shear to the shaft capacity of driven piles. Géotechnique 31, No. 1, $143-157$.

\title{
Application of the calculus of variations to the vertical cut off in cohesive frictionless soil
}

\author{
DE JOSSELIN DE JONG, G. (1980). Géotechnique 30, No. 1, 1-16
}

\section{E. Castillo and A. Luceño, University of Santander}

The Author is to be congratulated on the introduction of the second variation in the analysis. In effect, the Legendre, Jacobi and Weierstrass conditions cannot be omitted in the search for an extremum. Luceño (1979) and Luceño \& Castillo $(1980 \mathrm{a}, \mathrm{b})$ introduced these conditions in the analysis of several existing variational methods in soil mechanics problems and demonstrated that Baker \& Garber's and Chen's methods do not lead to extrema.

With respect to the Paper, the Author demonstrates that functional (21a) subject to (21b) and (21c) does not attain a minimum because, in an analysis of the second variation, the Jacobi condition is violated. This conclusion would have been better obtained by an analysis of the first variation which includes not only the Euler equation but also the transversality condition. This last condition is not satisfied by the solution given in the Paper, as it will be shown.

A straightforward check of the transversality condition leads to some problems because the auxiliary function $H$ depends on $\alpha_{F}$, but due to the fact that the Kötter conditions (32) and (33) must be satisfied by every potential slip line, the class of these lines can be initially reduced to those satisfying Kötter's conditions. With this assump- tion $\alpha_{\mathrm{F}}$ and $\beta_{\mathrm{F}}$ become constants and the Euler equation remains unchanged. So the same class of extremals (25) is obtained.

The transverality condition now becomes (Bolza)

$$
\bar{x}^{\prime} H_{x^{\prime}}+\left.\bar{y}^{\prime} H_{y^{\prime}}\right|_{\mathbf{F}}=0
$$

where

$$
\begin{aligned}
& \bar{x}(s)=s \\
& \bar{y}(s)=2 h / 3
\end{aligned}
$$

are the equations of the free surface $\mathrm{CD}$ in parametric form.

Substitution of expressions (23) and (D2) in (D1) leads to

$$
\begin{aligned}
& 1-g_{2} y-\frac{2}{1+\left(y^{\prime} / x^{\prime}\right)^{2}} \frac{y^{\prime}}{x^{\prime}}\left[\left(g_{1}+g_{2} x\right)-\left(1-g_{2} y\right) \frac{y^{\prime}}{x^{\prime}}\right] \\
& +\left.2\left[\beta_{\mathrm{F}}+\arctan g\left(\frac{y^{\prime}}{x^{\prime}}\right)\right]\left(g_{1}+g_{2} x\right)\right|_{\mathrm{F}}=0
\end{aligned}
$$

Taking into account (25a) and introducing (34) in the left-hand side of (D3) one gets a value of 1.865 which is obviously not zero. In consequence, the first variation does not vanish because the transversality condition is violated.

This fact demonstrates that Kötter's conditions are not compatible with the transversality condition in the point $F$. 


\section{REFERENCES}

Bolza. O. (1973). Lectures on the calculus of variations. New York: Chelsea Publishing Company.

Luceño, A. (1979). Analisis de los métodos variacionales aplicados a los problemas de estabilidad en Mecánica del Suelo. Utilización del teorema de la cota superior. PhD thesis, University of Santander.

Luceño, A. \& Castillo, E. (1980a). Evaluation of variational methods in slope analysis. In Proceedings of International Symposium on landslides, New Delhi.

Luceño, A. \& Castillo, E. (1980b). Análisis critico de los Métodos variacionales applicados a la estabilidad de taludes. Boletin de la Sociedal Española de Mecánica del Suelo y Cimentaciones.

\section{Author's reply}

These comments are very helpful and I entirely agree with them. The remark concerning the falsification of other proposed solutions by use of the standard variational verification theorems confirms statements made in my Paper; I am grateful for the support. The second remark concerns the possibility of falsifying my own solution in a manner that is even simpler and more direct than that which I used, by application of the transversality condition. The solution cannot satisfy boundary conditions and this requirement simultaneously and is therefore not an acceptable extremum. 